\title{
A Review of Cognitive Dissonance Theory and Its Relevance to Current Social Issues
}

\author{
${ }^{1}$ AZIZUL HALIM YAHYA, ${ }^{2}$ VIDI SUKMAYADI \\ ${ }^{1}$ Universiti Teknologi Mara (UiTM) Malaysia ${ }^{2}$ Universitas Pendidikan Indonesia, Bandung \\ Correspondence author: azizul928@salam.uitm.edu.my
}

\begin{abstract}
More than 60 years ago, Cognitive Dissonance Theory was introduced by Leon Festinger (1957), and arguably, this classic theory is still relevant to this day. Festinger described that cognitive dissonance occurs whenever people are confronted with facts that contradict their beliefs, values, and ideas; they will thrive on finding a way to resolve the contradiction to reduce their discomfort. The theory applies to all social situations involving the formation and changes of human attitude, and it is particularly pertinent to the process of decision-making and problem-solving. The relevance of the theory is still reflected today in the era of the Internet-of-Things (IoT). The information overload and exposure of conflicting opinions on the Internet lead people to a state of mental fatigue where they become confused to seek the right information and may result in social and psychological conflicts. Hence, this review paper attempts to provide an overview of the classic theory by exploring the core assumptions of the theory, causes of dissonance, and the theoretical implications on current social issues. It is expected that the results of the review could provide a sound basis for further practical study within the field of social studies.
\end{abstract}

Keywords: cognitive dissonance theory, festinger, social issues.

\section{Introduction}

The theory of cognitive dissonance was first introduced by Leon Festinger in 1957 and developed rapidly as an approach to understanding common areas of human psychology, communication, and social influence (Festinger, 1957). There are several theories that predate the area of psychological consistency or balance, including the theory of cognitive imbalance (Heider, 1946), Asymmetry theory as coined by Newcomb (Newcomb, 1953), and the congruity theory developed by Osgood and Tannembaum in their paper entitled "The Principle Of Congruity In The Prediction Of Attitude Change" (Osgood \& Tannenbaum, 1955).

As a development of the previous theories, cognitive dissonance theory is different in two important ways. First, the theory's objective moves beyond a theory of social behavior to a deeper understanding of the relationship between human behavior and cognition in general (Eddie Harmon-Jones \& Harmon-Jones, 2007; Shaw \& Costanzo, 1982). Secondly, this theory has been very influential in social psychology research compared to other consistency theories. In fact, in the past decade, we still found numerous scholars acknowledged the theory of cognitive dissonance as a widely recognized social theory and particularly for its significant and influential concepts in social psychology and human motivation areas (Griffin, 2012; E. Harmon-Jones, 2012; Lucas, 2009; McGrath, 2017; Morvan \& O'Connor, 2017).

Cognitive dissonance theory has become one of the most widely accepted approaches in explaining human behavioral change and many other social behaviors. This theory has been applied to more than tens of thousand studies and has the possibility of becoming an integrated part of social psychology theory for many years (Griffin, 2012; Hogg \& Vaughan, 2005; Nilsson, 2019). Accordingly, Festinger's cognitive dissonance

Received: 2020-09-12, Revised: 2020-10-27, Accepted: 2020-12-30

Print ISSN: 0215-8175; Online ISSN: 2303-2499. DOI: https://doi.org/10.29313/mimbar.v36i2.6652

Accredited Sinta 2 based on the decree No.10/E/KPT/2019 until 2024. Indexed by DOAJ, Sinta, Garuda, Crossreff, Dimensions 
theory (CDT) has been frequently applied to the social science literature to explain and predict the motivational nature of dissonance in producing attitude and behavior change in decision making and the broader social community context (Hinojosa et al., 2016).

Today, as we confront the information saturation era, humanity faces desperately difficult decisions due to the information overload on the Internet. When people are exposed to opposing thoughts or arguments on the Internet, and they are not able to choose which the right one is, they experience cognitive dissonance. Most people are aware of their belief systems. Nevertheless, when people realize that there may be a whit of truth in other people's perspectives and ideas, it conflicts with their cognitive beliefs. Consequently, some of the emotions that we experience resulting from cognitive dissonance are dread, guilt, anger, frustration, anxiety, stress, and other psychosomatic conditions (Fontanari et al., 2012). Foreseeable, many individuals experience problematic behaviors as a result of cognitive dissonance.

Nevertheless, cognitive dissonance within the digital and information-saturated era constitutes a novel domain with largely unreviewed potential. In general, prior studies and reviews are limited to exploring the association of cognitive dissonance with human relations, health, and management related issues (Alfitman, 1996; Fadholi et al., 2020; Hinojosa et al., 2016; Hutagalung, 2016; Morvan \& O'Connor, 2017; Nugroho, 2020). Hence in this present paper, the authors focused exclusively on how cognitive dissonance plays a role in the current saturated information society.

This review is considered relevant since this theory's impact is still apparent in today's social development. The cognitive dissonance theory is up to the mark at modeling psychological changes for individuals in multiple social situations. That is why the theory is still relevant to explain human behaviors toward the massive flow of information and technological advancement.

Hence, this paper's main objective is to succinctly review the current state of the theory in connection with today's social issue in terms of how people deal with extensive information. In particular, exploring the cognitive dissonance of media and information consumers could provide insights on causes and potential responses of the users to information anxiety, which is particularly beneficial to the body of knowledge related to human social relations and mental state (Bai et al., 2019).

Theories provide a basis to understand how people learn and a way to explain, describe, analyze, and predict learning. In that sense, a theory could help us make more informed decisions around the blueprint, development, and delivery of learning. Based on the rationale above, in this paper, the authors provide an overview of the classic theory by exploring the theory's core assumptions, causes of dissonance, and the theoretical implications on current social issues, especially related to human behavior toward the massive amount of information. Insights into these aspects can be used as a reference for future studies

\section{Research Methodology}

The authors employed the secondary research method by using a thematic review in discussing the literature. Secondary research can provide a firm context for the study area within its broader discipline or issue. In addition, a thematic literature review is organized around a specified scope of issues to explore the corpus of theory that has accumulated in regard to current phenomena (Graham, 2011). This method is in line with this paper's objectives that aimed at providing a conceptual framework of how the theory of cognitive dissonance is still pertinent in today's fast-paced society.

The authors used existing scholarly sources (online and printed) from top tier publications as the data in conducting the review. Afterward, the data was reviewed, collated, and summarized in a thematic arrangement to expand the overall understanding of cognitive dissonance theory as a concept and its social implications in the digital society.

\section{Results and Discussion}

\section{Core Assumptions of the Theory}

According to Festinger (1957), people tend to seek consistency among their cognitions, such as beliefs and opinions. A cognitive system is defined as a complex, interacting set of beliefs, attitudes, and values that affect and are affected by behavior (Littlejohn \& Foss, 2008).

The theory highlighted that when there is an inconsistency (dissonance) between attitudes or behaviors, something has to be 
done to remove the dissonance. In terms of the discrepancy between attitudes and behavior, it is most likely that the attitude will change to accommodate the behavior (Festinger, 2002). In line with this, Hogg and Vaughan (2005) made clear that consistency is what people seek; people always want to act in ways that are in line with their beliefs, and they want to ensure that their beliefs and values are always right. In other words, when people's beliefs are challenged or when their behavior is not aligned with their beliefs, this creates dissonance, and people need to reduce the dissonance to feel more secure and comfortable.

As an illustration, Dissonance theory teaches us why changing our colleagues' or family members' political opinions is so tricky, if not impossible-significantly if he or she has invested effort, money, and time for the sake of their political choice. Naturally, people do not like to face uncertainty, especially if it related to what they are already believed. At the point where their political ideas are challenged, they experienced cognitive dissonance. Then, they tend to find justifications because they want to live according to their beliefs. They want to reduce the contradictions caused by cognitive dissonance by responding with defensiveness and a hardening of their belief no matter how objective and accurate the opposite ideas that they faced.

Festinger (1957) states that cognitive refers to any form of knowledge, opinions, beliefs, or feelings about a person or one's environment. These cognitive elements relate to real things or everyday psychological experiences in one's life. Three particular relations might exist between those cognitive elements (Littlejohn \& Foss, 2008). The first relationship is irrelevant (neither affects the other). As an illustration, there is almost no relation between the knowledge that jogging is good for health and the fact that winter never comes in a country such as Indonesia.

The second relationship is consonant, or a state when two elements are relevant and synchronized. As an illustration, a man who knows that if a person is exposed to rain, he would be wet, and indeed the person gets wet when he is sopping from the rain. In other words, a mental state that involves consonant cognitive elements means conformity between human cognitive elements and resulted in less cognitive anxiety (Cooper \& Carlsmith, 2015). The third cognitive relationship is dissonance, or a state when one cognitive element is followed by a denial (inconsistent) of the other elements. An illustration of this relationship can be seen in a case when a man who knows that if he is exposed to rain, he would be wet experience a dissonant when one day a person found that he or she was not soaked even that person was stuck in a middle of the pouring rain.

Dissonance turns out most often in situations where an individual must choose between two contrast actions or beliefs. Two individuals who have the same situation have different possibilities in particular conditions. This difference occurs in an individual's ability to tolerate dissonance, the method chosen to reduce dissonant conditions and the way an individual perceives a problem as consonant or dissonant (Shaw \& Contanzo, 1985). Hence, cognitive dissonance can be referred to as the discomfort feelings that arise when a person's attitude or behavior conflicts with the person's values and beliefs or when the person has to face new information that is contrary to his or her beliefs.

One good example of the theory can be seen in a case when a person knows that smoking is harmful (first cognition) while liking to smoke (second cognition). Both of the cognitions conflict with each other, and they cause what is known as cognitive dissonance. People adjust to cognitive dissonance in different ways. An individual might adapt by creating a new cognition, changing attitude, or by changing the behavior. Related to the example, a person could create a new cognition by claiming that many older people smoke since they were young, and now they are still in good health. This claim is then believed as their new cognition to justify their action.

This perpetual phenomenon attracts researchers to continue studying the cognitive dissonance within human society. In a study by Hutagalung (2016), she studied adolescent's permissive act toward free sex in a religiously conservative country. Her study findings indicated that the study informants who experienced dissonance made extra efforts in achieving cognitive consistency by looking for other information and reached out to those who have a similar experience that can support their choice of having premarital sex. Then, there was a study of denial as a mode of reducing cognitive dissonance when a person faces counter attitudinal behaviors (Gosling et al., 2006)

Another scholarly comparison can be seen in a recent experiment investigating how 
prone human cognition to inconsistency and its association to personal negative affectivity (Levy et al., 2018). During their experiments, participants were asked to read sentences ending with incongruous or congruent final words. The results of the first experiment created more negative implicit consequences for sentences with incongruent endings than for congruent endings. In the second experiment, the inclusion of self-reports and facial electromyography replicates these results. Hence, Levy et al. (2018) concluded that even simple discrepancies might lead to cognitive dissonance.

Based on the examples above, a person tends to create a new cognition or belief to relieve the conflict that results from cognitive dissonance. It is more of what the person wants to believe rather than the fact. Thus, it can be said that since cognitive dissonance triggers a great deal of emotional turbulence, many people start changing their attitudes for their own emotional and psychological comfort.

\section{Causes of Cognitive Dissonance}

Festinger (1957) described that the emergence of dissonance could be caused by two general situations, namely when new information occurs and when a decision making must be made, where the cognition of actions taken is different from opinions or knowledge that lead to other actions. Furthermore, Festinger (1957, 2002) explained such situations might be brought by at least four (4) causal factors.

First, logical inconsistency can be described as the logic of thoughts, arguments, or reasoning that contradict each other. For example, someone who believes that humans can reach the moon; on the contrary, also believes that humans cannot make a spaceship that can take them of the earth's atmosphere.

Secondly, cultural values; where a person's cognition from one culture is likely to be different in others' culture. As an illustration, an Indonesian or Malaysian who believes that eating using hands is a regular thing. At the same time, the custom is dissonant with the fact that the practice might be unacceptable in the British culture ethics of eating. A scholarly example of cultural dissonance is reflected in a cross-cultural investigation of cognitive dissonance and selfaffirmation effects on enthusiasm (HoshinoBrowne et al., 2005). Their study strengthens the notion that culture forms conditions that cause and mitigate dissonance.

The third causal factor of dissonance is Forced Compliance Behavior. This behavior occurs when a person is forced to perform actions that are not consistent with his or her beliefs. Consider a company accountant who is told to cover up an instance of financial swindle by his employer. The accountant believes this is wrong, yet he might be forced to do it in order to retain her job. In line with this, McLeod (2018) added that a person's forced compliance behavior could not be changed since the behavior was already occurred in the past, so dissonance will need to be reduced by re-evaluating his or her attitude to what they have done.

The last factor is one's prior experience. This dissonance will arise if a person's cognition is not consistent with his or her experience. For example, one time, a friend of mine, who has a great taste in choosing restaurants, recommends a new place downtown. I have no doubt and quickly trying it out. Unfortunately, the food was terrible, and the service was not okay, and this experience becomes my mental dissonance. Then I decide to bridge the dissonance by saying that I will try it again next time, but I will avoid going back to that restaurant due to my past experience and because I do not want to raise questions about my friend's level of taste again.

Based on the causal factors above, it can be summarized that dissonance occurs when an individual must choose between attitudes and behaviors that are in contrast with each other. Subsequently, dissonance can be minimized or removed by reducing the significance of the conflicting beliefs, finding new beliefs that change the balance, or eliminating the conflicting behavior or attitude.

Subsequently, numerous studies have shown that there are at least three most frequently used dissonance-reduction strategies. The first one is changing the dissonant behavior or belief. Although dramatic change is very difficult to happen in a case of deeply held beliefs and ideals such as religious values or political ideal, still values change is possible with a proper approach or persuasion (Auster, 1965; C. Harmon-Jones et al., 2017; Mustaquim, M. Nyström, 2014).

The second strategy is to add more supportive elements. When people face any 
inappropriate or uncomfortable situation with their mental beliefs, they often add more supportive new beliefs or behaviors about the situation because they try to adapt to the situation according to their current values (Festinger, 2002; McLeod, 2018). For instance, if one person failed during an academic test, as a response, the person can add a supportive belief that it happened because the examiner has a personal problem with the person. Gruber's related studies in 2003 and 2016 show that cognitive dissonance is purported to be a powerful motivator for change. In her studies, she emphasized that incorporating supportive new beliefs and proper mentoring in a nursing unit can construct effective and lasting change to improve the unit performance (Gruber-Page, 2016; Gruber, 2003).

The next most common strategy is Trivialization. Studies in 1995 and 2019 indicate that Trivialization is often used as a mental process to minimize the significance of the dissonance element by covering the dissonance with more positive images or achievements (Séré de Lanauze \& SiadouMartin, 2019; Simon et al., 1995). As an illustration, if a business owner fails in his project, he will try to cover the failure by demonstrating previous successful projects or achievements.

Based on the applied strategies above, it implies that Cognitive dissonance causes feelings of unease and tension. Thus, people impulsively try to relieve this discomfort by attempting different strategies.

\section{The implication of the Theory in To- day's Social Issues}

Cognitive dissonance theory has important implications in many real-life situations, mainly in decision making, forced compliance, and selective exposure to information for ensuring that a person's actions and attitudes are in harmony (Griffin, 2012). The first area of dissonance theory implicates in the decision-making process. Dissonance is a consequence that cannot be avoided by a decision-making process (Festinger, 1957). The dissonance is based on the fact that a person must deal with a conflicting situation before a decision can be made.

Regarding today's social issues, the implication can be illustrated in a presidential election case when a person has dissonance to vote just because his close family members have a different choice and information source. In bridging the dissonance, this person decided to lie to his family about his choice so that there will be no conflict in the family by admitting that he voted for the same person. This case is in line with an article by Zaria (2015), who reported that voters' decision making is not always influenced by logical considerations, but also by the subconscious and emotional attitude. This case supported the thesis by Festinger (1957), who stated that if a person knows that another person has an opinion that is contrary to his opinion, then that person will try to reduce the dissonance by changing his attitude or decision.

Forced compliance becomes the second area that is highlighted in this paper. Forced compliance is an authoritative demand that forces other individuals to make opinions or perform acts that violate their better judgment (Griffin, 2012). It focuses on the goal of changing an individual's attitude through a combination of persuasion and authority. Forced compliance has important practical implications for people with authority, such as parents, teachers, employers, or managers.

An example of this can be seen in several experiments (Festinger \& Carlsmith, 1959; Joule \& Azdia, 2003; Schellenberg \& Aronson, 1973), which indicates that excessive punishment or pressure might produce shortterm obedience but not underlying change. Similarly, in trying to encourage children to do their homework, parents ought to think carefully about offering enormous rewards for compliance. Such rewards can undermine the development of the children's positive attitudes toward assignments. In particular, "smaller incentives for freely chosen counterattitudinal behavior are more likely to produce underlying favorable attitudes toward that behavior" (O'Keefe, 2015).

Another implication of the theory is reflected in people's selective exposure to information. Festinger's hypothesis argued that information selection correlates with the power of dissonance. To avoid dissonancearousing situations, people prefer to be exposed to information supporting their current beliefs rather than contrasting information (Morvan \& O'Connor, 2017). As an illustration of this state, the selective exposure hypothesis explains why most political conservatives In the U.S. only watch TV broadcasts of the Republican convention, and liberals stick to coverage of the Democratic conclave (Griffin, 
2012). Cognitive dissonance theory in the political area indicated that since votes are an expression of preference or beliefs, even the decision of voting might cause someone to defend the actions of the candidate for whom they voted by any means necessary (Mundkur, 2016). As a result, even a friendly and warm conversation could go awry when politics comes across as a topic (Sukmayadi \& Effendi, 2018).

Furthermore, the rise of the Internet of things (IoT) comes with its own challenges, particularly on the way people handling the "tsunami" of information from the Internet. In this era of digital society, the current spreading of bias and fake news on the Internet can be related to this cognitive dissonance phenomenon. People can now create content unburdened by the layers of editing and fact-checking that news outlets adhere to. Also, people can now select the information that is more consonant with their beliefs.

People fall for bias and fake news because they choose to read or spread the fake news since that is what they want to trust. For example, in the Indonesian context, $65 \%$ of the population is very prone to fake news, and this percentage is considered one of the highest in the world (Rania, 2018). Moreover, due to people's vulnerability to fake news, it is reported that hoax stories hamper Indonesia's fight against the infamous Covid-19 pandemic (Dursin, 2020). The proliferation of fake, fabricated, distorted, or skewed social information in a nation of over 237 million that currently carries the largest number of fatalities and accidents in Southeast Asia is such a danger to public health as a whole. The information overload and exposure of conflicting opinions on the Internet lead people to a state of mental fatigue where they become confused to seek the right information and may result in social as well as psychological conflicts.

To put it in a nutshell, the implication of the cognitive dissonance toward our society in dealing with extensive information can be seen in the following figure.

Based on Figure 1. The extensive information created a dissonance that conflicting people's prior antecedents. In consequence, people will attempt to reduce the dissonance by using defensive approaches or taking the least dissonant path as long as they can ease the psychological conflicts when they are overloaded by information.

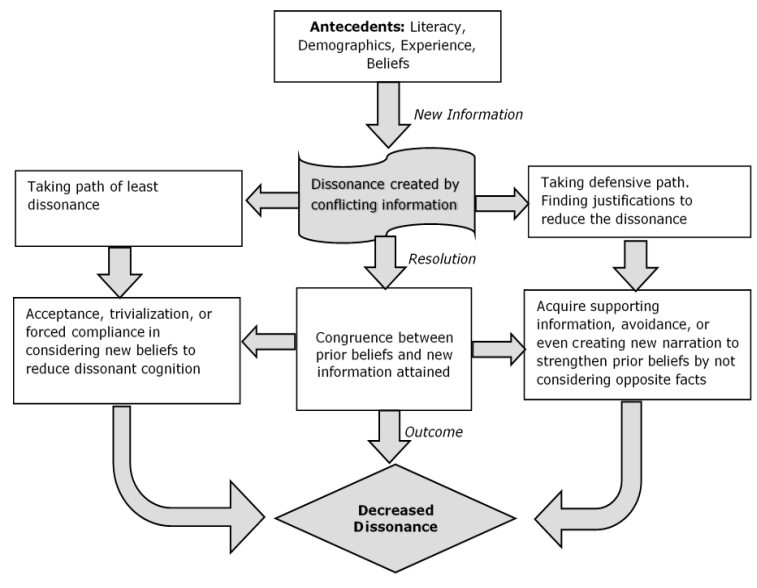

Figure 1. Visual Representation of Reducing Cognitive Dissonance caused by Extensive Information

This phenomenon cannot be separated from how digital media could affect people cognitive. Digital media, along with all its algorithms, can bridge its users into a realm of digital cognitive illusion or a reality built from the initial prejudice, which then builds unconscious awareness (which is firmly attached) to the existing reality (Fuchs, 2015). It can be said that the cognitive illusion is one of the essential factors that make people keep falling for news manipulation and carried away in spreading fake news. Indeed, the current technological advancement and the Internet of things are essential to assist people in living and working smarter and gaining complete control over their lives but be aware not to let technology evolve beyond our control.

People tend to believe their cognition based on their comfort zone to reduce the dissonance that they might face when receiving news that challenged their beliefs. In other words, the notion of "I might trust my news media but not your news media or the other news media" and a reader's tendency toward motivated cognition makes it hard to accept anything from conflicting sources. What can we derive from this case? As synthesized from Agarwal (2017), Bavel and Pereira (2018), one's alignment to a particular belief or concept is often an essential part of how people construct their identities. Hence, a threat to his or her belief is often viewed (but not always consciously) as a threat to self.

This phenomenon takes us to a classic work by Festinger (1957), who observed a doomsday cult to see what would happen if the world did not end on the date that the community leader had predicted. Instead of abandoning the faith when the prophecy 
was not fulfilled, the cult followers did the opposite by doubling their confidence and advocating more fervently. It is only one significant example of how people overcome their conflicting beliefs by performing what psychologists call "cognitive dissonance." Thus, an individual will actively seek and make choices on information and situations congruent with their attitudes and beliefs while refusing the conflicting notions.

\section{Conclusions}

This thematic review paper established the significance of cognitive dissonance theory. Even now, the theory coined by Leon Festinger is still relevant in explaining and predicting human behavior, significantly when they change their attitude or behavior to accommodate the dissonance due to acquiring extensive information. One of the apparent social implications of Cognitive Dissonance Theory is that people's behavior can be persuaded or even altered by creating significant dissonance through forced compliance, counter-attitudinal advocacy, or selected information exposure to contradict the person's cognitive state.

Although Festinger never specified a practical way to detect and determine a person's dissonance level, the theory has formed a strong foundation and source for other relevant research in human communication and psychology. The authors do hope that this thematic literature review could contribute to stimulating further theoretical expansion and empirical studies into the manifestations of cognitive dissonance within the broader communications area, particularly in new media contexts.

\section{Acknowledgment}

The authors are immensely grateful to Professor Atie Rachmiatie as the chief of Indonesia Communication Scholars Association, West Java Chapter, for her support and invaluable insights in improving the manuscript.

\section{References}

Agarwal, I. (2017). Why Fake News Is So Darn Shareable and Facts Are So Hard to Believe. Medium.Com. https://medium. com/s/news-is-breaking/trust-in-news3c9afc15d3a1

Alfitman. (1996). Konstruk Disonansi Kognitif dalam Penelitian Perilaku Konsumen:
Apakah Popularitasnya sudah Meredup? Universitas Andalas.

Auster, D. (1965). Attitude Change and Cognitive Dissonance. Journal of Marketing Research, 2(4), 401-405. https://doi. org/10.1177/002224376500200409

Bai, J., Kong, Q., Li, L., Wang, L., \& Zeng, D. (2019). Exploring cognitive dissonance on social media. 2019 IEEE International Conference on Intelligence and Security Informatics, ISI 2019, October, 143-145. https://doi.org/10.1109/ ISI.2019.8823262

Cooper, J., \& Carlsmith, K. M. (2015). Cognitive Dissonance. In International Encyclopedia of the Social \& Behavioral Sciences (pp. 76-78). Elsevier. https:// doi.org/10.1016/B978-0-08-0970868.24045-2

Dursin, K. (2020, July 6). Hoax stories hamper Indonesia's Covid-19 fight. Bangkok Post. https://www.bangkokpost.com/opinion/ opinion/1946480/hoax-stories-hamperindonesias-covid-19-fight

Fadholi, F., Prisanto, G. F., Ernungtyas, N. F., Irwansyah, I., \& Hasna, S. (2020). Disonansi Kognitif Perokok Aktif di Indonesia. Jurnal RAP (Riset Aktual Psikologi Universitas Negeri Padang), 11(1), 1. https://doi.org/10.24036/rapun. v11i1.108039

Festinger, L. (1957). A theory of social cognitive dissonance (1st Editio). Row, Peterson and Company.

Festinger, L. (2002). Behavioral Support for Opinion Change. Public Opinion Quarterly. https://doi.org/10.1086/267263

Festinger, L., \& Carlsmith, J. M. (1959). Cognitive consequences of forced compliance. Journal of Abnormal and Social Psychology. https://doi.org/10.1037/ h0041593

Fontanari, J. F., Bonniot-Cabanac, M.-C., Cabanac, M., \& Perlovsky, L. I. (2012). A structural model of emotions of cognitive dissonances. Neural Networks, 32, 57-64. https://doi.org/10.1016/j. neunet.2012.04.007

Fuchs, C. (2015). Culture and Economy in the age of digital media (1st Editio). Routledge.

Gosling, P., Denizeau, M., \& Oberlé, D. (2006). Denial of responsibility: A new mode of dissonance reduction. Journal of Personality and Social Psychology, 90(5), 722-733. https://doi.org/10.1037/00223514.90.5.722

Graham, V. F. (2011). The literature review: a step-by-step guide for students. Evaluation 
\& Research in Education, 24(3), 224-225. https://doi.org/10.1080/09500790.2011. 583140

Griffin, E. A. (2012). A first look at communication theory (8th ed.). McGrawHill, Inc.

Gruber-Page, M. (2016). The Value of Mentoring in Nursing: An Honor and a Gift. Oncology Nursing Forum, 43(4), 420-422. https://doi.org/10.1188/16.ONF.420-422

Gruber, M. (2003). Cognitive Dissonance Theory and Motivation for Change. Gastroenterology Nursing, 26(6), 242245. https://doi.org/10.1097/00001610200311000-00005

Harmon-Jones, C., Haslam, N., \& Bastian, B. (2017). Dissonance reduction in nonhuman animals: Implications for cognitive dissonance theory. Animal Sentience: An Interdisciplinary Journal on Animal Feeling, 1(12), 4.

Harmon-Jones, E. (2012). Cognitive Dissonance Theory. In Encyclopedia of Human Behavior: Second Edition. https:// doi.org/10.1016/B978-0-12-3750006.00097-5

Harmon-Jones, Eddie, \& Harmon-Jones, C. (2007). Cognitive Dissonance Theory After 50 Years of Development. Zeitschrift Für Sozialpsychologie. https://doi. org/10.1024/0044-3514.38.1.7

Heider, F. (1946). Attitudes and Cognitive Organization. Journal of Psychology: Interdisciplinary and Applied. https://doi. org/10.1080/00223980.1946.9917275

Hinojosa, A. S., Gardner, W. L., Walker, H. J., Cogliser, C., \& Gullifor, D. (2016). A Review of Cognitive Dissonance Theory in Management Research: Opportunities for Further Development. Journal of Management, 43(1), 170-199. https:// doi.org/10.1177/0149206316668236

Hogg, M. A., \& Vaughan, G. M. (2005). Social Psychology. Pearson Education. https:// books. google. com. my/books? id = 3CUPWAACAAJ

Hoshino-Browne, E., Spencer, S. J., Zanna, M. P., Zanna, A. S., Kitayama, S., \& Lackenbauer, S. (2005). On the cultural guises of cognitive dissonance: The case of Easterners and Westerners. Journal of Personality and Social Psychology, 89(3), 294-310. https://doi.org/10.1037/00223514.89.3.294

Hutagalung, I. (2016). Disonansi Kognitif Pada Perilaku Seks Pranikah. Jurnal Komunikasi Ikatan Sarjana Komunikasi Indonesia, 1(2), 71. https://doi.org/10.25008/jkiski. v1i2.52
Joule, R. V., \& Azdia, T. (2003). Cognitive dissonance, double forced compliance, and commitment. European Journal of Social Psychology. https://doi.org/10.1002/ ejsp. 165

Levy, N., Harmon-Jones, C., \& Harmon-Jones, E. (2018). Dissonance and discomfort: Does a simple cognitive inconsistency evoke a negative affective state? Motivation Science, 4(2), 95-108. https:// doi.org/10.1037/mot0000079

Littlejohn, S. W., \& Foss, K. A. (2008). Theories of Human Communication. In Theories of Human Communication.

Lucas, S. E. (2009). The Art of Public Speaking (10th ed.). McGraw-Hill.

McGrath, A. (2017). Dealing with dissonance: A review of cognitive dissonance reduction. Social and Personality Psychology Compass, 11(12), e12362. https://doi. org/10.1111/spc3.12362

McLeod, S. A. (2018). Dissonance can be reduced in one of three ways: Forced Compliance Behavior. Simply Psychology. https://www.simplypsychology.org/ cognitive-dissonance.html

Morvan, C., \& O'Connor, A. J. (2017). A theory of cognitive dissonance. In A Theory of Cognitive Dissonance. https://doi. org/10.4324/9781912282432

Mundkur, P. (2016). Is there Cognitive Dissonance in Politics? Linkedin. https:// www.linkedin.com/pulse/cognitivedissonance-politics-prabhakar-mundkur/

Mustaquim, M. Nyström, T. (2014). Designing Persuasive Systems For Sustainability- A Cognitive Dissonance Model. Proceedings of the 22nd European Conference on Information Systems (ECIS), 9-11. http://urn.kb.se/resolve?urn=urn:nbn:s e:uu:diva-224680

Newcomb, T. M. (1953). An approach to the study of communicative acts. Psychological Review. https://doi. org/10.1037/h0063098

Nilsson, M. (2019). Motivations for Jihad and Cognitive Dissonance-A Qualitative Analysis of Former Swedish Jihadists. Studies in Conflict and Terrorism, O(0), 1-19. https://doi.org/10.1080/105761 0X.2019.1626091

Nugroho, F. S. (2020). DISONANSI KOGNITIF ORANG DENGAN HIV/AIDS (ODHIV) DI SURABAYA DALAM KONDISI RESILIENSI. Commercium, 03(02), 1-5.

O'Keefe, D. J. (2015). Persuasion: Theory and Research. SAGE Publications. https://books.google.com.my/ books?id =IFLWBgAAQBAJ 
Osgood, C. E., \& Tannenbaum, P. H. (1955). THE PRINCIPLE OF CONGRUITY IN THE PREDICTION OF ATTITUDE CHANGE. Psychological Review. https://doi. org/10.1037/h0048153

Rania, D. (2018, March 22). Berdasarkan Survei, $65 \%$ Warga Indonesia Gampang Percaya Hoax. Itu Termasuk yang Tertinggi di Dunia. Hipwee. https://www. hipwee. com/feature/berdasarkan-survei-65warga-indonesia-gampang-percaya-hoaxitu-termasuk-yang-tertinggi-di-dunia/

Schellenberg, J. A., \& Aronson, E. (1973). The Social Animal. Contemporary Sociology, 2(4), 397. https://doi. org/10.2307/2062049

Séré de Lanauze, G., \& Siadou-Martin, B. (2019). Dissonant cognitions: from psychological discomfort to motivation to change. Journal of Consumer Marketing, 36(5), 565-581. https://doi.org/10.1108/ JCM-07-2017-2279

Shaw, M. E., \& Costanzo, P. R. (1982). Theories of social psychology. McGraw-
Hill. https://books.google.com.my/ books?id=RgK4AAAAIAAJ

Simon, L., Greenberg, J., \& Brehm, J. (1995). Trivialization: the forgotten mode of dissonance reduction. Journal of Personality and Social Psychology, 68(2), 247-260. https://doi.org/10.1037/00223514.68.2.247

Sukmayadi, V., \& Effendi, R. (2018). Social Media Emotion in Politics: An Indonesian Case Study of Political Environment on Facebook. IOP Conference Series: Earth and Environmental Science, 145, 012009. https://doi.org/10.1088/17551315/145/1/012009

Van Bavel, J. J., \& Pereira, A. (2018). The Partisan Brain: An Identity-Based Model of Political Belief. Trends in Cognitive Sciences, 22(3), 213-224. https://doi. org/10.1016/j.tics.2018.01.004

Zaria, G. (2015, June 3). The hidden psychology of voting. BBC News. https://www.bbc.com/indonesia/vert_ fut/2015/06/150601_vert_fut_voting. 